\title{
Metallic Card Clothing and Its Teeth
}

By Kiyoshi Mizukaga, MEMBER, TMSJ

Shinko Boki Co., Ltd., Ogaki

\section{Introduction}

Metallic card clothing for use on carding machines for the rayon and cotton spinning processes has been in service in Japan since 1954. It has created a "sensation" in the textile industry. Reports of many instances of its trial use have been published thick and fast. More recently, reports of the results of comparative tests of metallic card clothing and fillet card clothing have been published.

Numerous studies have been made as to the angle density of the teeth of metallic clothing and their results announced. On the more important details-the shape of the teeth, their appearance when ground, their hardness-few, if any, published studies have been made. The author has made experiments concerning these details and presents his findings here.

\section{Merits and Demerits of Metallic Clothing}

\section{1-I. Merits}

(1) It does not need periodical grinding. Fillet clothing does once every 7 to 10 days.

(2) It does not need stripping. Fillet clothing does once every 3 to 4 hours.

(3) Metallic clothing, because it needs no stripping, involves no problem of an after-stripping change in the quality of card web or in the grains of slivers. Fillet clothing does.

(4) It reduces wastage.

\section{1-2. Demerits}

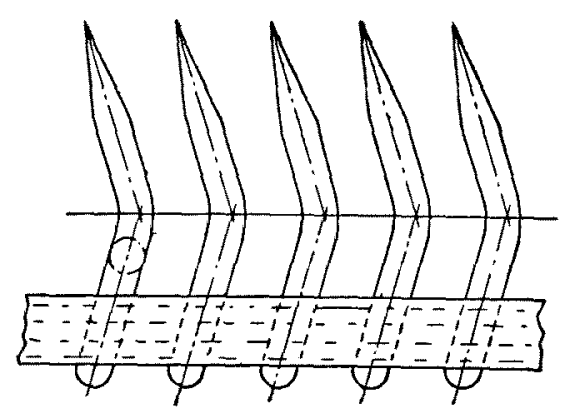

Fig. 1. Fine points of teeth of fillet clothing with sharp fine-points.
(1) Metallic clothing has less fiber-holding force than fillet clothing. Therefore, fibers often get off the metallic clothing of doffers, and web often droops in wavy fashion where the doffer comb is. A large amount of fibers off card clothing results in irregularity and breakage of slivers.

(2) Irregularity of laps results more directly in irregular card web than when fillet clothing is used for carding. The thin part of laps sometimes makes holes in web. The thick part does not receive sufficient carding action for card web to transfer smoothly from the doffer to the doffer comb. Too thin or thick laps break card web. With web broken, card web often gets in between the cylinder and the doffer comb and damages the wire-points of metallic clothing of the cylinder. Damaged metallic clothing is difficult to repair. Fillet clothing is seldom damaged and, if damaged, is easy to repair.

(3) Metallic clothing produces a slightly higher rate of fiber-breakage than does fillet clothing. Of course, even fillet clothing shows a high rate of fiber breakage when its card clothing is replaced, but the rate of breakage gradually decline with time.

(4) Metallic clothing is subject to irregularity in the height of the teeth, mainly because it is mechanically difficult to make teeth of a uniform shape by punching and also because, as a rule, any one carbon steel band of which metallic clothing is made lacks uniformity of quality and receives sectionally different degrees of force form punching, although the force of punching is uniform. Irregularity in the height of teeth can be corrected by grinder after winding, but it is difficult to correct the grindinginduced difference between teeth in the dimension of the fine point.

\section{Teeth of Metallic Card Clothing}

2-1. Dimension of Fine Points of Teeth

If the fine-points of fillet clothing are ground to

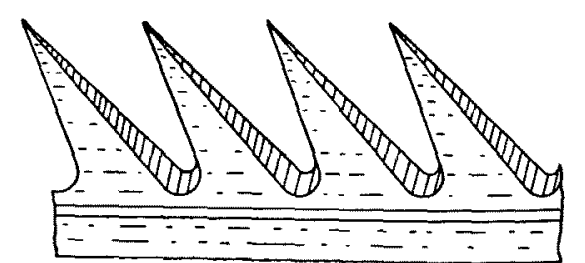

Fig. 2. Fine points of teeth of metallic clothing with sharp fine-points. 
the sharpness of a sewing needle, its clothing does not do enough carding action to remove neps and dust, no matter how good its opening action (see Figure 1).

Metallic clothing with sharp fine-points, such as is shown in Figure 2, does not give enough carding action. The author has detected that most defects in, and difficulties with, metallic clothing occur if its fine-points are too sharp. The same is true of fillet clothing, too.

The fine-points of the teeth of metallic clothing, like the points of the wires of fillet clothing, instead of being needle-sharp, should have a certain dimension. It is also imperative that the tooth points as well as the sides of the wires of metallic clothing have suitably coarse snicks (see Figures 3 and 4 .)

To improve the carding action of metallic clothing, what size area, or what dimension, should the top of wire have? The results of the author's initial experiment, made with metallic clothing of the sharpness shown in Figure 2, are as follows:

(1) Unsatisfactory carding action.

(2) Small fiber-holding force.

(3) Occasional drooping of web and frequent web breakage during operations.

From these results the author concluded that the tooth-points of metallic clothing should not be needle-sharp but needed some "room" and snicks. He then ground the tooth-points of metallic clothing until they were $0.2 \times 0.2 \mathrm{~mm}$ in dimention, as shown

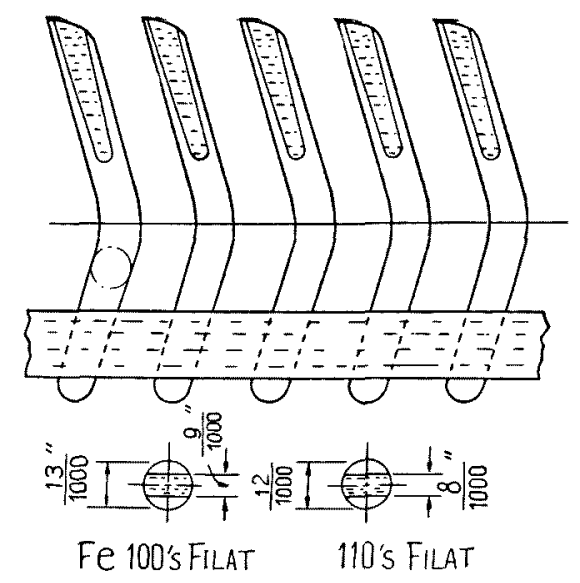

Fig. 3. Fine points of teeth of fillet clothing having small "room" on fine points.

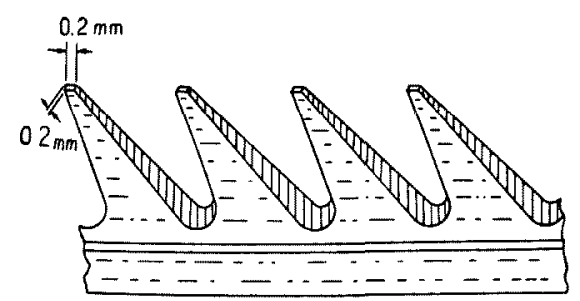

Fig. 4. Fine points of teeth of metallic clothing having small "room" on fine points. in Figure 4, and made snicks on them. This improved the quality of card web and strengthened fiber-holding force. As a further experiment, he ground the tooth-points of the same metallic clothing until they were $0.3 \times 0.2 \mathrm{~mm}$ in dimension. This gave the best quality web and reduced neps.

From the results of these tests the author has found that metallic clothing as well as fillet clothing needs fine-points not needle-sharp but at least $0.2 \times$ $0.2 \mathrm{~mm}$ in dimension and suitably coarse snicks. Complete carding action is unobtainable unless metallic clothing has suitable coarseness on the top plain of the wire.

We have found from experiment that the same principle of carding action governs metallic clothing and fillet clothing.

The snicks on the tooth-points and sides of metallic clothing for the cylinder, for flat and for the doffer must be mutually adjusted in the degree of coarseness.

\section{Snicks on the Sides of the Wire}

Metallic clothing, like fillet clothing, needs snicks on the sides of the wire. The degree of the coarseness of the snicks has an important bearing on metallic clothing as well as on fillet clothing. Figure 3 shows the appearance of the snicks made on the sides of the wire of fillet clothing.

As for fillet clothing, the snicks on the sides of

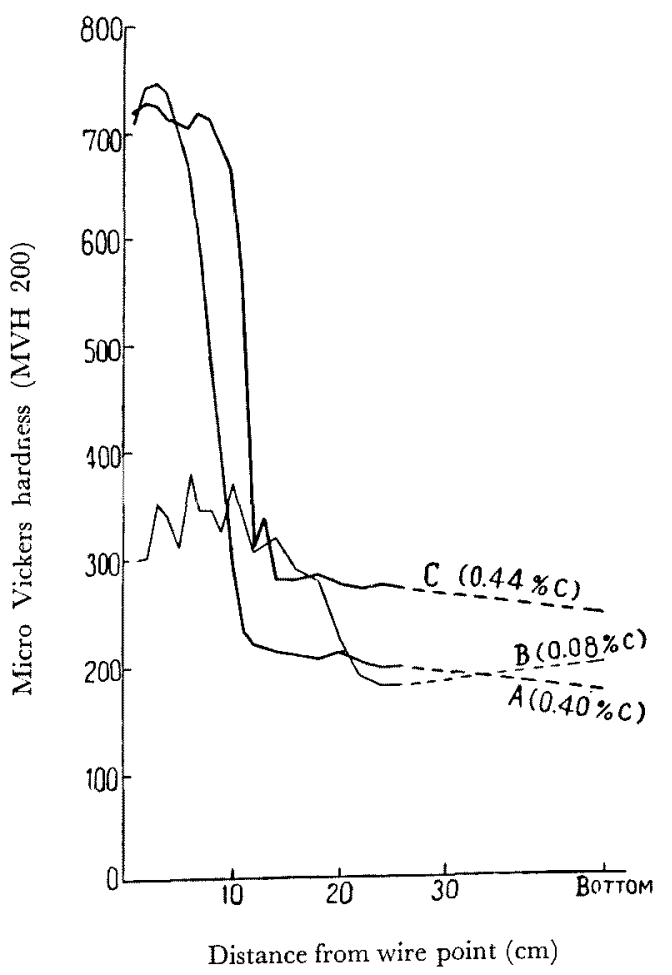

Fig. 5. A graph of the degree of hardness of metallic clothing made by three different manufacturing companies. 
the wire can be "produced" by the side grinder.

As for the metallic clothing, the snicks on the sides of the wire are "produced" by the passage of the wire through the dice during the drawing process.

3-1. Relation between the Coarseness of Snicks on the Sides of the Wire and Carding Action

(1) Coarse snicks have a large fiber-holding force but produce a high rate of fiber breakage.

(2) Worn-out snicks diminish in fiber-holding force and cannot open small tufts of fibers completely.

3-2. How to Keep the Snicks on the Sides of the Teeth of Metallic Clothing Permanently
The snicks on the sides of fillet clothing, when worn out, can be restored by side grinder. Those on metallic clothing installed on the cylinder and doffer cannot be restored when worn out. To keep the snicks wear-proof permanently, harder steel bands must be used for metallic clothing.

Figure 5 shows a graph of the degree of hardness of metallic clothing made by three different manufacturing companies. Company A's metallic clothing is $710^{\circ}$ in hardness at $0.1 \mathrm{~mm}$ from the top of the wire; $740^{\circ}$ (maximum) at $0.3 \mathrm{~mm} ; 290^{\circ}$ at $1 \mathrm{~mm}$; and $210^{\circ}$ at $1.2 \mathrm{~mm}$. Company B's metallic clothing is $715^{\circ}$ in hardness at the top of the wire; $720^{\circ}$ (maximum) at $0.2 \mathrm{~mm}$ from the top; $685^{\circ}$ at $1.4 \mathrm{~mm}$; and $185^{\circ}$ at $2.1 \mathrm{~mm}$. Company C's metallic clothing is $300^{\circ}$ in hardness at the top of the wire; $380^{\circ}$ (maxi-

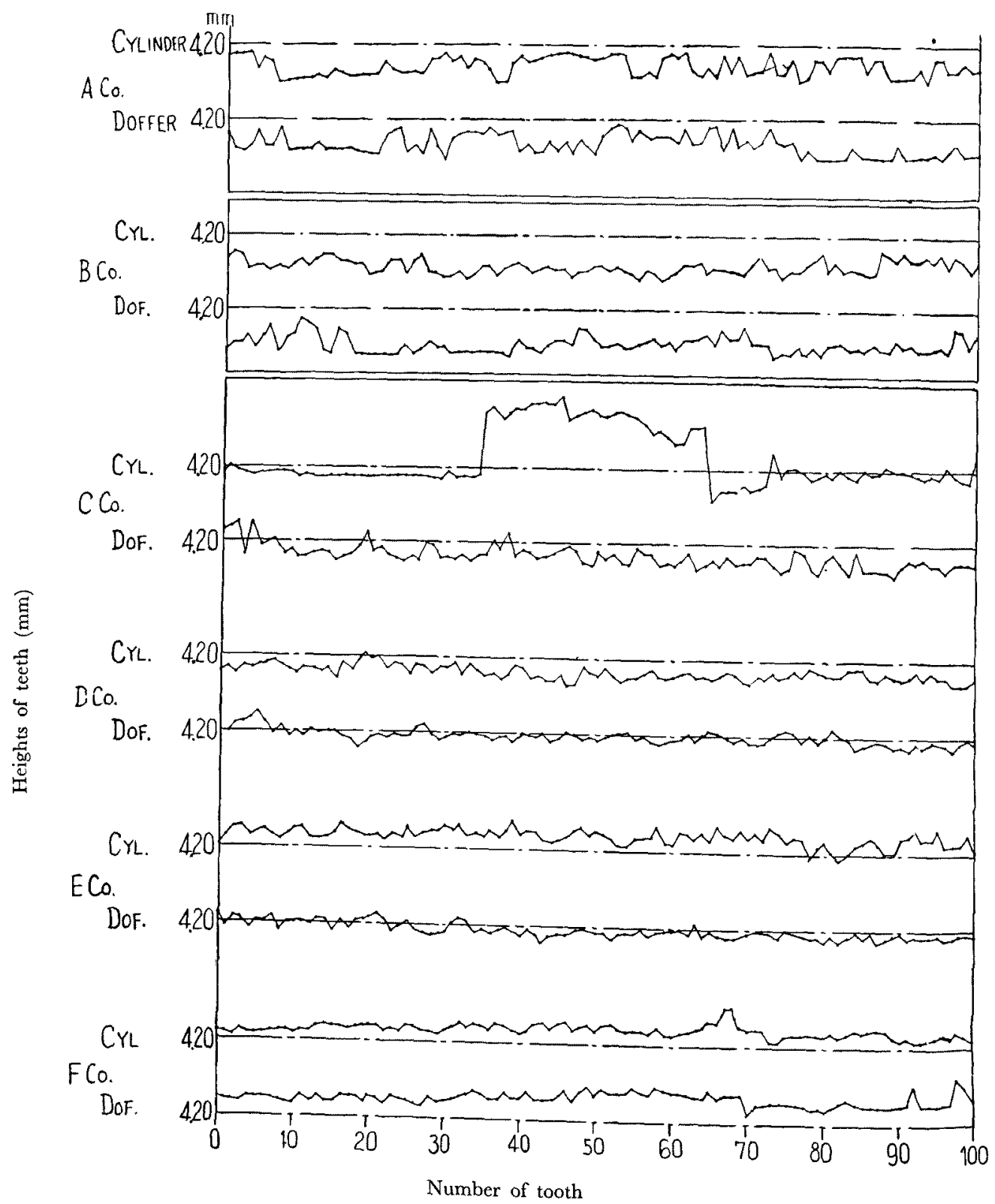

Fig. 6. A diagram of the heights of the teeth of metallic clothing made by six companies. 
Table. 1. Height of Teeth of Metallic Clothing Made by Six Companies.

\begin{tabular}{|c|c|c|c|c|c|c|c|c|}
\hline & \multicolumn{4}{|c|}{ Clothing for cylinder } & \multicolumn{4}{|c|}{ Clothing for doffer } \\
\hline & \multicolumn{2}{|c|}{ Height of teeth } & \multirow[b]{2}{*}{$\begin{array}{l}\text { Difference } \\
\text { (mm) }\end{array}$} & \multirow[b]{2}{*}{$\begin{array}{c}\text { Mean value } \\
(\mathrm{mm})\end{array}$} & \multicolumn{2}{|c|}{ Height of teeth } & \multirow[b]{2}{*}{$\begin{array}{c}\text { Difference } \\
\text { (mm) }\end{array}$} & \multirow[b]{2}{*}{$\begin{array}{c}\text { Mean valuo } \\
(\mathrm{mm})\end{array}$} \\
\hline & $\begin{array}{c}\text { Maximum } \\
(\mathrm{mm})\end{array}$ & $\begin{array}{c}\text { Minimum } \\
(\mathrm{mm})\end{array}$ & & & $\begin{array}{c}\text { Maximum } \\
(\mathrm{mm})\end{array}$ & $\begin{array}{c}\text { Minimum } \\
(\mathrm{mm})\end{array}$ & & \\
\hline Co. A & 418 & 410 & 8 & 414.5 & 416.5 & 409 & 7.5 & 412 \\
\hline Co. B & 415 & 407 & 8 & 410.8 & 417 & 409 & 8 & 411.2 \\
\hline Co. G & 425 & 418 & 7 & 423 & 420.5 & 415.5 & 5 & 418.5 \\
\hline Co. D & 420.5 & 412 & 8.5 & 415.8 & 422 & 414 & 8 & 419.3 \\
\hline Co. $\mathrm{E}$ & 438 & 411 & 27 & 423 & 425 & 412 & 7 & 419.2 \\
\hline Col.F & 429 & 423 & 6 & 423 & 426 & 423 & 3 & 424.4 \\
\hline
\end{tabular}

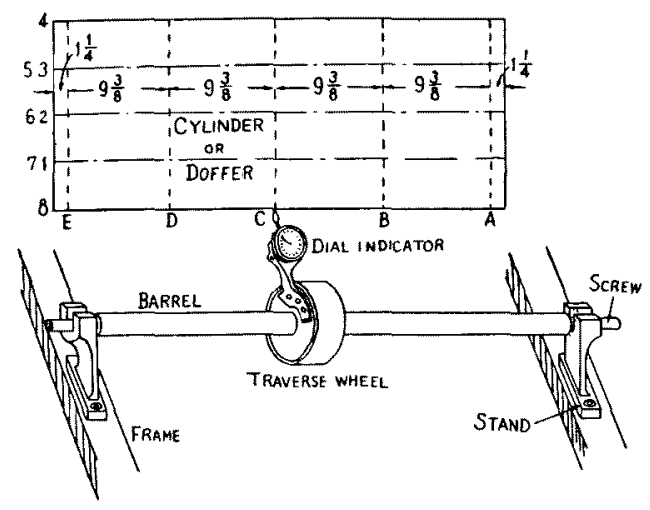

Fig. 7 Tester to survey the surface of cylinder or doffer.

mum) at $0.6 \mathrm{~mm}$ from the top. (The hardness degrees mentioned are determined by a Micro Vickers Hardness Tester.)

Each manufacturer's product is hardened until $1 \mathrm{~mm}$ from the top-point of the wire. Therefore, irregularity of height may be attributed to the fact that the hardened parts of wire-teeth become irregular in dimension by grinding. Irregularity in the height of wires is undesirable if the snicks on the wires are to be kept wear-proof permanently.

Only the top of the teeth must be hardened; the bottom must not. Otherwise, it is difficult to wind metallic clothing around the cylinder or the doffer.

\section{Irregularity in the Height of Teeth of Clothing}

Metallic clothing having teeth irregular in height lead to various difficulties in carding action and cannot reduce the space between the cylinder and the doffer to less than 4/1,000 inch. Metallic clothing must be made regular in height, but this is very difficult.

Figure 6 shows the diagram of the heights of the teeth of metallic clothing made by six companies, including the three referred to earlier. Table 1 shows the maximum and minimum heights of those teeth. The metallic clothings of companies A, B, D, E and $\mathrm{F}$ differ only slightly in wire-tooth height; company C's metallic clothing for cylinders differs noticeably
(1) Number of neps (in 10 grains of card sliver)

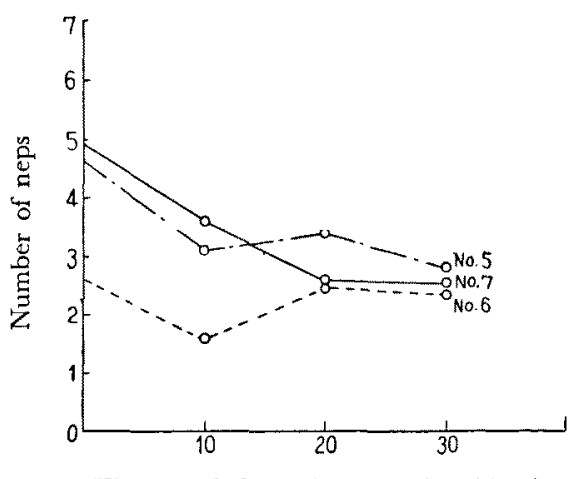

Time needed for the opcration (days)

(2) Mean staple length (cut-length $56 \mathrm{~mm}$ )

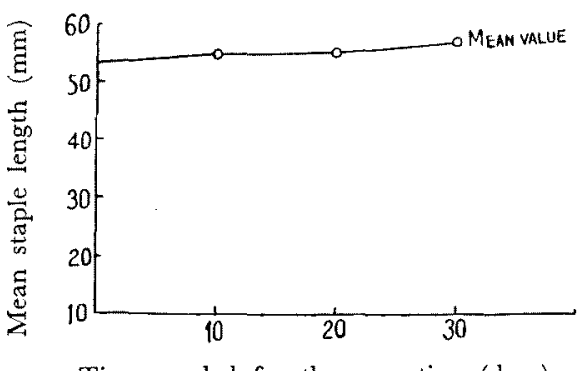

Time needed for the operation (days)

(3) Percentage of length deviation

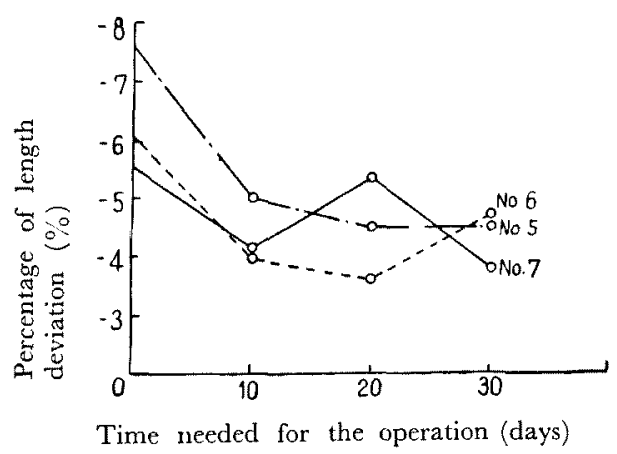

Fig. 8. Results of experimental use of metallic clothing.

from the other five's. Irregularity in the wire-tooth height of metallic clothing within a range of 2.5 and $3 \mathrm{~mm}$ is permissible. 
Table 2. Irregularity of the Surface of a Cylinder and a Doffer

(Unit: $1 / 1,000$ inch)

\begin{tabular}{|c|c|c|c|c|c|c|c|c|c|c|c|c|c|c|c|c|c|}
\hline \multirow{3}{*}{$\begin{array}{l}\text { Circum- } \\
\text { ferencial } \\
\text { direction }\end{array}$} & \multicolumn{16}{|c|}{ Lateral length direction } & \multirow{3}{*}{$\begin{array}{l}\text { Maximum } \\
\text { irregularity } \\
\text { after } \mathrm{G} * * *\end{array}$} \\
\hline & \multicolumn{4}{|c|}{$E$ (left) } & \multicolumn{3}{|c|}{ D } & \multicolumn{3}{|c|}{ C (center) } & \multicolumn{3}{|c|}{$\mathrm{B}$} & \multicolumn{3}{|c|}{ A (right) } & \\
\hline & & $\mathrm{B}^{*}$ & W** & $G^{* * * *}$ & B & W & $G$ & B & W & $G$ & B & W & G & B & W & G & \\
\hline \multirow{8}{*}{ Cylinder } & 1 & +0.5 & +0.3 & 0 & +0.3 & -1.7 & -0.3 & -0.2 & -3.8 & -1 & +0.2 & -3 & -0.5 & 0 & 0 & 0 & 1 \\
\hline & 2 & +0.1 & +2 & -0.5 & +0.7 & +2 & -0.5 & 0 & +3.3 & -0.5 & +0.2 & -1.5 & -0.5 & 0 & -1 & 0 & 0.5 \\
\hline & 3 & +0.2 & +1.5 & -1 & +0.1 & -1 & -0.7 & -0.2 & -4 & -1 & 0 & -2.7 & -0.5 & 0 & -1 & 0 & 1 \\
\hline & 4 & 0 & +1 & -0.3 & +0.2 & -1.8 & -0.3 & 0 & -2.2 & -0.7 & +0.2 & -3 & -0.3 & 0 & -1 & -0.2 & 0.5 \\
\hline & 3 & 0 & +2 & 0 & +0.1 & -1.3 & 0 & -0.1 & -4 & -0.5 & +0.1 & -1.8 & -0.3 & 0 & -0.8 & 0 & 0.5 \\
\hline & 6 & +0.3 & +1.3 & -0.3 & +0.2 & -1 & -1.3 & 0 & -3.8 & -0.5 & +0.2 & -3 & -0.5 & 0 & -0.8 & 0 & 1.3 \\
\hline & 7 & +0.2 & +0.7 & -0.5 & +0.2 & +2 & -0.7 & -0.1 & -2 & -1 & +0.1 & -3 & -1 & 0 & -1 & 0 & 1 \\
\hline & 8 & +0.2 & +2.3 & -0.3 & +0.3 & +0.3 & -1.3 & 0 & -3.0 & -0.5 & +0.5 & -2 & -0.5 & 0 & -0.5 & -0.2 & 1.1 \\
\hline \multicolumn{2}{|c|}{$\begin{array}{l}\text { Maximum } \\
\text { irregularity }\end{array}$} & 0.5 & 2.2 & 0.5 & 0.6 & 3.8 & 1.3 & 0.2 & 3.8 & 0.5 & 0.5 & 2.8 & 0.7 & 0 & 1 & 0.2 & \\
\hline \multirow{8}{*}{ Doffer } & 1 & 0 & +0.8 & 0 & -0.1 & -0.7 & +0.5 & -0.1 & -1.3 & +0.8 & +0.1 & 0 & +1 & 0 & 0 & 0 & 1 \\
\hline & 2 & 0 & +0.5 & 0 & -0.6 & 0 & 0 & -0.3 & +1 & +0.5 & +0.1 & -0.5 & +1 & 0 & 0 & 0 & 1 \\
\hline & 3 & 0 & +1 & 0 & -0.6 & -1.3 & +0.7 & -0.4 & +1 & +0.5 & 0 & -0.7 & +1.2 & 0 & 0 & +0.5 & 1.2 \\
\hline & 4 & 0 & +0.7 & +0.3 & -0.5 & 0 & +0.8 & -0.3 & +1 & +1 & +0.1 & +0.3 & +1 & +0.1 & +1 & +0.3 & 0.7 \\
\hline & 5 & -0.2 & +0.3 & +0.5 & -0.6 & 0 & +0.7 & -0.3 & -1 & +0.5 & 0 & 0 & +1.2 & 0 & +0.5 & 0 & 1.2 \\
\hline & 6 & -0.2 & +1.7 & 0 & -0.6 & 0 & +0.3 & -0.3 & -0.5 & +0.8 & 0 & 0 & +1 & 0 & +0.5 & 0 & I \\
\hline & 7 & -0.1 & +1 & 0 & -0.7 & +0.5 & +1 & -0.2 & -1 & +0.7 & 0 & -0.3 & +1 & 0 & 0 & 0 & 1 \\
\hline & 8 & -0.2 & +0.8 & 0 & -0.5 & -0.5 & +0.3 & -0.2 & -1.5 & +0.7 & +0.1 & -1 & +1 & 0 & 0 & 0 & 1 \\
\hline \multicolumn{2}{|l|}{$\begin{array}{l}\text { Maximum } \\
\text { irregularity }\end{array}$} & 0.2 & 1.4 & 0.5 & 0.6 & 1.8 & 1 & 0.3 & 1 & 0.5 & 0.1 & 1 & 0.2 & 0.1 & 1 & 0.5 & \\
\hline
\end{tabular}

Note: $\quad *^{B}$ is the values measured after grinding of cylinder and doffer. **W is the values measured after winding the metallic clothing on cylinder and doffer. ${ }^{* * *} \mathrm{G}$ is the values measured after grinding the teeth of metallic clothing.

\section{Surface of Cylinder and Doffer}

No matter how uniform wire-teeth may be in height, good carding action is unobtainable if the cylinder or the doffer is deformed in any way. The surface of the cylinder and doffer must be ground with high precision.

5-1. Tester to Survey the Surface of Cylinder or Doffer

Figure 7 shows a high-precision tester for this purpose. The tester, converted from a traverse wheel grinder, is of the author's device. It has a dial indicator on the traverse wheel, which is attached to a barrel supported by two stands. Figure 7 shows a schematic diagram of the high-precision tester, which is capable of surveying irregularity of the circumferencial direction and the lateral length direction.

To survey a deformation of the cylinder or the doffer by this tester, the following prerequisites must be met:

(1) A deformation of the shaft of the cylinder or doffer must be reduced to less than $1 / 100 \mathrm{~mm}$.

(2) The surface of the shaft must be precisely ground with a bare surface grinder.

(3) The surface of the cylinder or doffer must be uniformly surveyed in the circumferencial and lateral directions as shown in Figure 7.
Table 2 shows the values obtained by the tester.

\section{Results of Experimental Use of Metallic Clothing}

We have surveyed how many neps and broken fibers there are when a card is operated for 30 days after metallic clothing is wound round the cylinder and doffer. Figure 8 shows the results of the survey. The number of neps and broken fibers is considerably large immediatcly after the winding of new wire, but therefater, beings to decrease gradually and becomes nearly constant after 30 days.

Judging from his experiments, the author considers that metallic clothing gets into good condition if a card is operated for one or two months on end after installation of new metallic clothing.

\section{Conclusions}

The carding action of metallic clothing and fillet clothing is governed by the same principle. However, a carding machine equipped with metallic clothing gives many advantages, including reduced wastage and dispensing with stripping, to say nothing of better quality card slivers per equal unit of production. 